\title{
Considerations for admission to the medical-surgical postgraduate programs at the University of Cartagena: 6 years of observation.
}

\author{
Virna Caraballo Osorio ${ }^{\# 1}$, Rita Sierra Merlano ${ }^{\# 2}$, Marlene Duran Lengua ${ }^{\# 3}$ \\ ${ }^{\text {\#} S c h o o l ~ o f ~ M e d i c i n e, ~ U n i v e r s i d a d ~ d e ~ C a r t a g e n a ~}$ \\ 130015 Cartagena de Indias, D. T. y C., Colombia \\ 1vcaraballoo@unicartagena.edu.co, 2rrmagola@unicartagena.edu.co \\ 3 mduranl@unicartagena.edu.co
}

\begin{abstract}
The aim of this study was to know about the considerations of those admitted to the medicalsurgical postgraduate programs at the University of Cartagena. An observational descriptive methodology was implemented using the databases of the Graduate Department of Medicine. It was noted that the largest number of applicants are from the University of Cartagena followed by the University of Sinu, however in the last year 2017 the second place of admissions, corresponded to graduates of the University of Antioquia.
\end{abstract}

Keywords: Faculty of Medicine, Medical specialties, admission.

\section{INTRODUCTION}

A selection of specialties implies a transformation from the undifferentiated undergraduate stage to a completely differentiated professional enterprise, where all future efforts would focus on a single specialized field of medical discipline [1].The evolving landscape of the medical field through innovative and creative developments in technologies has a profound impact on the selection of clinical specialties [2]. In addition, socio-economic and organizational factors also strongly influence the dynamics of medical specializations.

Over the past 10 years, the medical profession has broadly opened its doors to women and society, undergoing profound changes, such as the 35-hour work week in some European countries [3]. Medical students have not been spared from these changes and only a few are willing to participate in surgical careers, judged by many to be too restrictive and sometimes underestimated [4].Residents who are currently on the road to surgery are primarily those who have had some contact with surgery during their previous training (called "externat" in France). The situation is complex and several factors influence the choice of students for one or another surgical subspecialty (previous contact with the subspecialty, quality of life, possible income, type of activity) [3].Beyond the challenges inherent in educating and training future generations of general surgeons, surgical educators face the potentially daunting task of identifying successful training candidates who may be successful in their programs and are unlikely to drop out.

On the other hand, with an emphasis on Colombia, the national supply of medical programs has increased in recent years by just over $150 \%$ from $21 \%$ in 1992 to $64 \%$ in 2015. In some cases, the regional supply is growing much more rapidly [5]. From the 288 institutions of higher education (HEI) registered in Colombia, 64 have qualified registries, Decree 1295 [6] and graduate from 3,500 to 4,000 doctors each year approximately [7].In Cartagena there are 3 Universities with qualified registration that offer training in Medicine and each year 300 doctors graduate approximately.The offer of spots for surgical medical specialties in our country is limited, which in addition to having a working register by the Ministry of National Education, must have an adequate infrastructure, qualified teaching resources and practice scenarios for disciplinary training [5, 7,]. In 2015, the Faculty of Medicine of the University of Cartagena offered a total of 53 spots for 11 surgical medical specialties, and 1,475 doctors were registered to participate in the selection process. The American Medical Association accepts 207 medical-surgical specialties in 38 groups[8]. Currently, the University of Cartagena has 12 surgical medical specializations and an availability of 55 spots for annualized cohorts. This year (2017) a total of 1,710 doctors from different regions of Colombia were enrolled, and graduates from different medical schools, both public and private.

The shortage of spots for medical surgical specialties at the national level has made the selection process for students, especially in public universities, very stressful and demanding. The UDC in order to assign the spots to professionals with better academic merits, in order to select students with greater academic merits and competencies. This means that the level of requirement to obtain a spot gives a "high value" to each one, it is tacitly intended that, with the same instrumentation and information of the traditional selection process, those 
students are admitted in which it is prejudged that they will have an adequate course during their training practices, and an optimal performance in the professional practice as specialists. The admission process for medical surgical specialties in public universities is usually carried out under the principles of equality and transparency [7].

The University of Cartagena seeks to select the candidates with the best results in the general knowledge test, which has an assigned value of $80 \%$, but also those with the best academic average, additional studies of continuing education, publications, participation in research groups visible in the GRUPLAC, with a level of English B2 or higher according to the Common European Framework of Reference for Languages (CEFR). The previous attributes are part of the curriculum grade, which has a value of $10 \%$ of the total score, the other $10 \%$ corresponds to the interview a test carried out by teachers in the area.Since 2006, the Faculty of Medicine from the University of Cartagena examination for admission to the surgical postgraduate medical degree programs has been conducted by the University of Antioquia, in order to guarantee the transparency of the process. This institution prepares, applies, qualifies the exam, and finally submits the results to the Department of Postgraduate and Continuing Education of the Faculty of Medicine of the University of Cartagena, to continue the selection process. Eligible applicants with the highest scores are considered eligible, selecting up to double the number of spots offered for each specialization. These applicants continue the selection process by submitting their resume, performing a psycho-technical test and finally the interview with teachers from the Faculty of Medicine, ending the process with the publication of the names of the students admitted.It is not easy to enter a medical-surgical postgraduate program at a public university, the University of Cartagena currently offers 55 spots in the 12 postgraduate programs with a valid qualified registration. At the moment, we do not know the percentage of doctors graduated from the country's universities who have access to a spot in the surgical medical postgraduate programmes at the Faculty of Medicine of the University of Cartagena. Since 2008, there has been a gradual increase in the number of registrations and the number of spots offered in the surgical medical specialties, figures that are shown in figure 1.

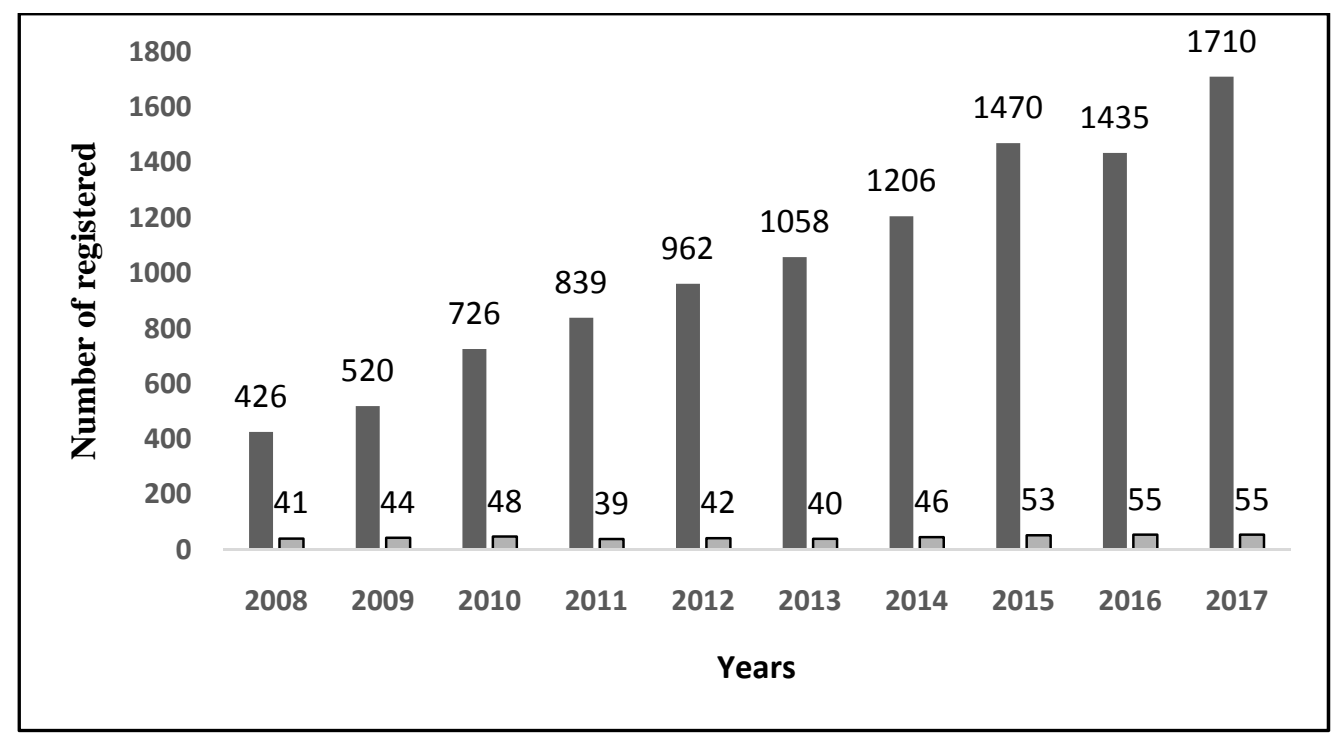

Figure I. Registered and Admitted to the Medical-Surgical Calls for Proposals of the University of Cartagena, year 2008-2017

At present, it is not known what percentage of those admitted to medical-surgical specialties are graduates of the different universities in Colombia and how this percentage has varied from 2012 to 2017. This study will be useful to know indirectly academic and formative aspects of the graduates of the different medical schools that are admitted in the medical specialties of the $\mathrm{U}$ of Cartagena.

\subsection{Background}

The Law 30 of 1992 regulated higher education and provided the legal conditions that facilitated the increase of Medical Faculties and in general of all disciplines in parallel, The country has been implementing a series of quality assurance instruments, both general and specific to higher education and health, which have had an impact on the training of doctors, trying to remedy two situations that arose with the increase in the number of programmes: the lack of regulation of these programmes and the deterioration of the teaching and service relations [5].

The examinations of the quality of Higher Education -ECES- for students in the undergraduate medical programmes, constitute a state examination modality for the external evaluation of last year medical students and form part, with other processes and actions, of a set of instruments that the National Government has at its disposal to evaluate and improve the quality of higher education. The aim of these examinations is, among other 
things, to verify minimum levels of knowledge of last year's undergraduate students in general, and others, to certify and validate qualifications in higher education studies carried out abroad [6].

High quality accreditation before the National Accreditation Council (CNA) is a very important instrument for the promotion and recognition of the quality of medical schools. The Accreditation process is a voluntary process, it is necessary to install mechanisms that stimulate the linkage of all the country's programs. But the quality of medical education does not depend exclusively on the university institution [5]. Part of the curricular contents are developed in hospitals and health centers under the service teaching agreements, and in these settings different training institutions converge with different educational projects and often do not have a structure that allows them to administer the teaching and the faculty loses the possibility of monitoring and evaluating the training processes and control the academic development of each program. The aim of this study was to determine those admitted graduates from the different medical schools of the country who enter the medical-surgical specialization programs of the Faculty of Medicine of the University of Cartagena from 2012 to 2017.

\section{Materials AND Methods}

The methodology implemented was descriptive-observational, using the database of the Graduate Department of Medicine, a review was made of the number of students who entered each medical school in the country.

A. Data source

A study was conducted taking into account 6 years from 2012 to 2016. Academic and investigative aspects of those admitted to medical surgical specializations and the University were studied. The Systems Division of the University of Cartagena was asked for information on those admitted to medical-surgical specialties in the calls 2012,2013,2014,2015,2016 and 2017. A database was also developed in Excel with the following variables: full name, age, gender, name and character of the public or private HEI, where they obtained their medical degree. Descriptive statistics were used for data analysis.

\section{RESUlTS AND Discussions}

Since 2012, the majority of those admitted to the Medical Surgical Convocations come from the University of Cartagena with percentages of $42.9 \%$ in $2012,40 \%$ in $2013,43.48 \%$ in $2014,24.52 \%$ in $2015,32.73 \%$ in 2016 and 40\% in 2017 Table 1.

Table 1: Percentage of HEI Graduates Admitted for Public Universities in the Medical-Surgical Calls for Proposals 2012-2017.

\begin{tabular}{cccccccc}
\hline & $\mathbf{2 0 1 2}$ & $\mathbf{2 0 1 3}$ & $\mathbf{2 0 1 4}$ & $\mathbf{2 0 1 5}$ & $\mathbf{2 0 1 6}$ & $\mathbf{2 0 1 7}$ & Average \\
\hline UDC & 42.9 & 40 & 43.48 & 24.52 & 32.73 & 40 & 37.27 \\
UDEA & 2.4 & 7.5 & 10.87 & 7.54 & 7.27 & 10.9 & 7.75 \\
UIS & 2.4 & 0 & 2.17 & 9.43 & 7.27 & 5.45 & 4.45 \\
U V & 2.4 & 0 & 2.17 & 3.77 & 3.63 & 0 & 2.00 \\
UMG & 0 & 0 & 2.17 & 1.88 & 9 & 0 & 2.18 \\
UN & 0 & 0 & 2.17 & 1.88 & 0 & 3.64 & 1.28 \\
U C & 4.8 & 2.5 & 0 & 0 & 1.82 & 5.45 & 2.43 \\
UTP & 0 & 0 & 2.17 & 1.88 & 1.82 & 7.27 & 2.19 \\
UQ & 0 & 0 & 0 & 3.77 & 1.82 & 1.82 & 1.24 \\
UT & 0 & 0 & 0 & 1.88 & 1.82 & 1.82 & 0.92 \\
U T P & 0 & 0 & 0 & 0 & 3.6 & 0 & 0.60 \\
USC & 0 & 0 & 0 & 1.88 & 0 & 1.82 & 0.62 \\
UP & 0 & 0 & 0 & 0 & 0 & 1.8 & 0.30 \\
UNN & 0 & 0 & 0 & 0 & 0 & 1.8 & 0.30 \\
ETM & 0 & 0 & 2.2 & 0 & 1.8 & 0 & 0.67 \\
\hline
\end{tabular}

Note:UDC: Universidad de Cartagena, UDEA: Universidad de Antioquia, UIS: Universidad Industrial de Santander, UV: Universidad del Valle, UMG: Universidad del Magdalena, UN: Universidad Nacional, UC: Universidad de Caldas, UTP: Universidad Tecnológica de Pereira, UQ: Universidad del Quindío, UT: Universidad del Tolima, UTyP: Technological and Pedagogical University of Colombia, USC: Universidad Surcolombiana, UP: University of Pamplona, UNÑ: University of Nariño, ETM: Latin American University of Medicine (La Habana-Cuba). 
In 2012, the majority of those admitted came in order of frequency from the University of Cartagena, followed by University of the Sinú, U. del Norte, University of the North, Universidad Libre of Barranquilla, Pontifical Bolivarian University, University of Caldas and Javeriana University, where it can be seen that the largest number of admitted students were graduates of the region's universities. (Figure 1 and 2). This research also shows that the number of applicants for medical programs is different each year, as well as the public or private nature of the Universities of origin of those admitted varies each year.

Figure 2. Percentage of Absorption of Applicants from Different Private Medical Faculties.

\begin{tabular}{lrrrrrrc}
\hline & $\mathbf{2 0 1 2}$ & $\mathbf{2 0 1 3}$ & $\mathbf{2 0 1 4}$ & $\mathbf{2 0 1 5}$ & $\mathbf{2 0 1 6}$ & $\mathbf{2 0 1 7}$ & Average \\
\hline UNISINU & 9,5 & 10 & 10,87 & 9,43 & 9 & 5,45 & $\mathbf{9 , 0}$ \\
U LIBRE & 4,8 & 2,5 & 6,52 & 9,43 & 0 & 0 & $\mathbf{3 , 9}$ \\
UNINORTE & 7,1 & 5 & 2,17 & 5,66 & 0 & 0 & $\mathbf{3 , 3}$ \\
UMETROPOLITANA & 2,4 & 5 & 2,17 & 1,88 & 1,82 & 1,82 & $\mathbf{2 , 5}$ \\
U S MARTIN & 0 & 5 & 0 & 5,66 & 3,63 & 3,64 & $\mathbf{3 , 0}$ \\
CURN & 2,4 & 10 & 4,35 & 0 & 1,82 & 1 & $\mathbf{3 , 3}$ \\
UAB & 2,4 & 2,5 & 2,17 & 0 & 1,82 & 0 & $\mathbf{1 , 5}$ \\
EMJC & 2,4 & 2,5 & 0 & 0 & 1,82 & 0 & $\mathbf{1 , 1}$ \\
U JAVERIANA & 4,8 & 2,5 & 0 & 0 & 0 & 0 & $\mathbf{1 , 2}$ \\
UPB & 4,8 & 2,5 & 0 & 0 & 0 & 0 & $\mathbf{1 , 2}$ \\
U. DE LA SABANA & 0 & 2,5 & 0 & 0 & 0 & 0 & $\mathbf{0 , 4}$ \\
U. DEL BOSQUE & 2,4 & 0 & 0 & 0 & 0 & 0 & $\mathbf{0 , 4}$ \\
U. DEL CES & 2,4 & 0 & 0 & 0 & 0 & 0 & $\mathbf{0 , 4}$ \\
UCVC & 0 & 0 & 0 & 0 & 1,82 & 1,82 & $\mathbf{0 , 6}$ \\
C REMINGTONG & 0 & 0 & 0 & 0 & 0 & 1,82 & $\mathbf{0 , 3}$ \\
U ROSARIO & 0 & 0 & 0 & 0 & 0 & 1,82 & $\mathbf{0 , 3}$ \\
U Del BOSQUE & 2,4 & 0 & 0 & 0 & 0 & 0 & $\mathbf{0 , 4}$ \\
UCC & 0 & 0 & 0 & 0 & 3,6 & 0 & $\mathbf{0 , 6}$ \\
\hline
\end{tabular}

Note: CURN: Rafael Núñez University Corporation, UAB: Universidad Autónoma de Bucaramanga, EMJC: Juan Corpas School of Medicine, UPB: Pontifical Bolivarian University, UCVC: Central University of Valle del Cauca, UCC: Colombian Cooperative University.

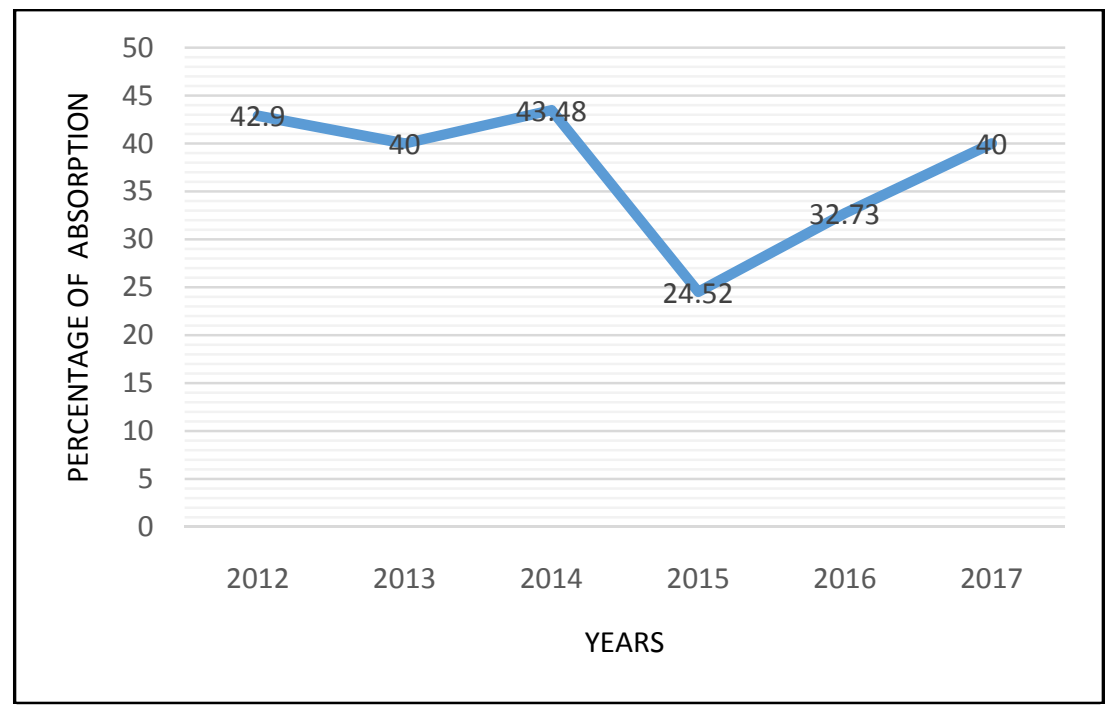

Figure 3. Percentage of Absorption of Graduates from the University of Cartagena in their Medical-surgical Postgraduate Year 2012-2017. 
In 2014,43.48\% of those admitted to the medical-surgical postgraduate programmes came from the University of Cartagena and is the highest figure in the last 5 years. In the following years, although there was an increase in the spots for medical surgical specialties, there was a decrease in the percentage of admitted graduates from the UDC.In 2015, the spots increased from 46 to 53 and it was the year in which fewer UOC graduates entered the medical surgical postgraduate programmes. In 2016, the spots were increased to 55 and the percentage of university admissions increased to $32.73 \%$. In 2017 the percentage of university graduates increased compared to the previous year $(40 \%)$. Statistical analysis showed a $\mathrm{p}<0.001$ when comparing the number of admissions from the University of Cartagena with those from other universities. However, with respect to those admitted graduates of the University of Cartagena, each year from 2012 to 2017, there was no statistical significance.

It is not easy to enter a surgical-medical specialty in a public university in Colombia, there are few spots for the number of doctors who aspire and the selection processes must discriminate and thus choose those who perform better tests of knowledge, for the case of the University of Cartagena is taken into account those who provide documents that accredit training in research, continuing education, knowledge of English and work experience among others. The fact that the general knowledge test for the selection process of the University of Cartagena is conducted by the University of Antioquia indirectly assesses the quality of medical education at our University. The University of Antioquia has international recognition and has been ranked as one of the best in the country. The applicants, among those graduates of the University of Cartagena, are subjected to a highly complex general knowledge test and many graduates manage to be eligible and continue the selection process.The lack of young surgeons will be a problem in the future if efforts are not made to reverse this issue. For Japan, the recruitment of doctors from rural areas has been particularly difficult; therefore, attractive special programmes were launched in 2008. Scheduled surgical specialist programs can lead to the development of subspecialty experience in each field such as thoracic, cardiac, digestive, endocrine, and pediatric surgeries [9].

A recent prospective non-randomised cohort study exploring the evolution of medical students' interest in orthopaedic surgery, a similarly masculine field, showed that early exposure through literature and lectures increased the likelihood of applying in orthopedics. One interventionist study considered summer cardiac research programs as generators of student interest in surgical subspecialties, but did not focus on the interest of surgery in women. Efforts can be made to provide preclinical and clinical medicine students with early exposure to the field with the intention of increasing interest, informing on educational developments, dispelling misconceptions and facilitating mentoring[10, 11].

The results obtained in this study are an indirect measure of the evaluation of the quality of medical education at the Faculty of Medicine of the University of Cartagena. Even though the number of UDC applicants is higher, this does not guarantee the obtaining of spots since the knowledge test is taken by another University and represents $80 \%$ of the total score of the selection process.The majority of residents of each cohort are graduates of the University of Cartagena and if we add the Atlantic coast universities, the percentage is higher. In 2012 66.7\% of those admitted came from Universities of the Atlantic Coast, in 2013 67.5\%, in 2014 67.38\%, in 2015 58.46\%, in $201656.18 \%$ and in $201750.91 \%$. The results show an upward trend from 2012 to 2014. However, in 2015 the percentage of admitted graduates from the UDC gradually decreased until 2017, the phenomenon has been reversed showing a gradual decrease in the percentage of admitted students.

In the last call (2017-2) it is interesting to note that the second place in order of frequency was obtained by the University of Antioquia and the third place by the Technological University of Pereira. The proportion of those admitted to the UC medical specialization programs has diversified and among those admitted to the different specializations there are graduates from different regions of the country.If we review the studies conducted by Foote et al., [12], preclinical women had broad interests, including primary care specialties. Eighteen per cent of preclinical women, pediatrics by 16 per cent, obstetrics and gynecology by 11 per cent, surgery or surgical subspecialties by 21 per cent and medical subspecialties by 20 per cent. However, women in clinical years showed significantly greater interest in primary care-internal medicine or family medicine specialties $(31 \%, \mathrm{p}=$ 0.0124 compared to preclinical women). Among preclinical men, surgical and surgical subspecialties (50\%, $\mathrm{p}$ $<0.001$ compared to preclinical women) and subspecialties of internal medicine $(24 \%, p=0.0111)$ were the most popular in selecting a first option ().

The distribution of the six most popular reasons (lifestyle, intellectual challenge, possibility of private practice, and interest in a specific disease, possible admission and patient contact) differed according to the type of surgical activity. Lifestyle was favored mainly by future ophthalmologists (47/57.82\%), contact with patients by gynecologists (89/137.65\%), while only $43 \%$ of future plastic surgeons (21/49) listed a special interest in the disease and patients. As of 1 January 2007, there were 25,294 surgical specialists practicing in France: 62 per cent in private institutions, 31 per cent in public hospitals, 6 per cent in private institutions working with public hospitals and 1 per cent in other types of structures. The two key factors to be assessed to save the profession were: labor difficulty or resistance and financial compensation. The income of French surgeons is lower than that of other disciplines and lower than that of surgeons working in countries whose cost of living is comparable to that of France.Gender also has a major influence on the choice of surgical specialty, as reflected in 
gynecology and obstetrics: more than $80 \%$ of students who choose this specialty are women. As the proportion of women is high, this probably explains why this specialty is the first choice of students in general. As for the different surgical subspecialties, this study also confirms the lack of interest in certain specialties such as stomatology, thoracic and vascular surgery. The surgery was chosen by approximately one-third of the students. The type of activity depends on multiple factors (gender, lifestyle, income). To compensate for the lack of students in some of these specialty categories, there are several solutions: to make the underserved subspecialties more attractive (that is, to revalue the remuneration of various medical/surgical procedures) and to create specialty-specific clues. There are many reasons why surgery is not chosen as a specialty.

Lack of surgeons is an economic problem for France [13].If Colombia wants to continue training competent surgeons, dedicated to their profession and filling all subspecialties, the government must find ways to influence student choice and provide the means to enhance the profession for which the difficulties have been recognized.These results are attributed to the high quality of medical education provided at the Faculty of Medicine of the University of Cartagena. The medical student of the UDC has the opportunity to belong to research seedbeds from the first semesters and participate in research projects supported by Colciencias, has a large number of free courses that can choose according to their likes and motivations. Since the sixth semester, it has had direct contact with patients, in ideal settings with which agreements have been made, accompanied by a large number of teachers and faculty professors with a high academic level in the different areas of knowledge and teacher training. In boarding school (last year of formation) the student rotates through the different specialties and acquires a role of general practitioner with access to a large number of patients under the direct supervision of residents of the surgical medical specializations and their teachers and perform a theoretical deepening in health problems prevalent in our environment, throughout the year.

\section{CONCLUSIONS}

The proportion of students admitted to the University of Cartagena has varied and those are part of the different universities and regions of the country. The largest number of surgical medical students aspiring to specialization comes from local universities. During the observation period, the UDC still holds first place in terms of the percentage of admissions, although there has been an increase in the number of admissions of graduates from public universities based in the interior of the country. The training in research from the first semesters, the possibility of belonging to a research group and projects supported by Colciencias, the direct contact with a large number of patients, ideal scenarios and teachers with high academic training in different areas of knowledge and teacher training favor the performance and quality of the graduate of the University of Cartagena.

\section{REFERENCES}

[1] A. Parlak, S. Develıy,Y.E. Eyı. “Factors affecting the choice of health specialty by medical graduates”. Medical teacher, vol. 37, no. 7, pp. 702-703, 2015.

[2] M. Ibrahim, A. Fanshawe, V. Patel, K. Goswami, G. Chilvers, M. Ting,T. Athanasiou."What factors influence British medical students' career intentions?”. Medical teacher, vol. 36, no. 12, pp. 1064-1072, 2014.

[3] M. Rouprêt,Y. Pouliquen.“La chirurgie française doit-elle être secourue?”. La Presse Médicale, vol. 33, no. 20, pp. 1411-1413, 2004.

[4] L. Maggiori, A. Brouquet, J.D. Zeitoun, M. Roupret, J.H. Lefevre. "Avenir de la chirurgie viscérale en France: sondage sur 929 étudiants et résultats des choix des futurs internes après l'examen classant national 2008”. Journal de Chirurgie, vol. 146, no. 2, pp. 168-174, 2009.

[5] R.H. Rozo, R.H. Escobar. "La educación médica en Colombia”. Revista Med, vol. 19, no. 1, pp. 7-9. 2011.

[6] Decreto 1295 del 20 de Abril de (2010). Por el cual se reglamenta el registro calificado de los programas académicos de educación superior programas académicos de educación superior Recuperado de http: http://www.mineducacion.gov.co/1621/articles229430_archivo_pdf_decreto1295.pdf

[7] R.J. Echeverry. "Aspectos generales y académicos de los* aspirantes y los* admitidos a la especialidad de pediatría de la Universidad Nacional de Colombia”. Revista de la Facultad de Medicina, vol. 63, no. 1, pp. 33-45, 2015.

[8] D.C. Goodman, E.S. Fisher, T.A. Bubolz, J.E. Mohr, J.F. Poage, J.E. "Wennberg, Benchmarking the US physician workforce: an alternative to needs-based or demand-based planning”. Jama, vol. 276, no. 22, pp. 1811-1817, 1996.

[9] A. Nanashima, S. Hidaka, T. Nonaka, N. Yamasaki, T. Tsuchiya, K. Matsumoto, T. Yasutake. "Recruitment of Young Medical Apprentices (RYOMA) project: A comprehensive surgical education program at a local academic institute in Japan”. Journal of surgical education, vol. 71, no. 4, pp. 587-592, 2014.

[10] K. Baldwin, S. Namdari, A. Bowers, M.A. Keenan, L.S. Levin,J. Ahn."Factors affecting interest in orthopedics among female medical students: a prospective analysis”. Orthopedics, vol. 34, no. 12, pp. e919-e932, 2011.

[11] L.L. Lattanza, L. Meszaros-Dearolf, M.I. O’Connor, A. Ladd, A. Bucha, A. Trauth-Nare,J.M. Buckley.“The Perry initiative’s medical student outreach program recruits women into orthopaedic residency”. Clinical Orthopaedics and Related Research ${ }^{\circledR}$, vol. 474, no. 9, pp. 1962-1966, 2016.

[12] D.C. Foote, J.M. Meza, V. Sood,R.M. Reddy.“Assessment of Female Medical Students' Interest in Careers in Cardiothoracic Surgery”. Journal of Surgical Education, vol. 74, no. 5, pp. 811-819, 2017.

[13] J.H. Lefèvre, L. Karila, S. Kerneis,M. Rouprêt.”Motivation of French medical students to pursue surgical careers: results of national survey of 1742 students”. Journal of visceral surgery, vol. 147, no. 3, pp. e181-e186, 2010. 


\section{AUTHORS PROFILE}

Virna Caraballo Osorio. Medical phisician, Especialist in Pathology, Especialist in Education, Professor of Pathology Universidad de Cartagena.

Rita Sierra Merlano, Medical phisician, Especialist in Internal Medicines, Especialist in Reumathology, Ph. D in Educación, Professor of Internal Medicine in Universidad de Cartagena.

Marlene Duran Lengua, Magister in Farmacology, Especialist in Biochemistry, PhD in Biomedical Sciences, Professor of Farmacology in Universidad de Cartagena. 